\title{
COMMENTARY
}

\section{Extravascular lung water and the pulmonary vascular permeability index may improve the definition of ARDS}

\author{
Azriel Perel* \\ See related research by Kushimoto et al., http://ccforum.com/content/16/6/R232
}

\begin{abstract}
The recent Berlin definition has made some improvements in the older definition of acute respiratory distress syndrome (ARDS), although the concepts and components of the definition remained largely unchanged. In an effort to improve both predictive and face validity, the Berlin panel has examined a number of additional measures that may reflect increased pulmonary vascular permeability, including extravascular lung water. The panel concluded that although extravascular lung water has improved face validity and higher values are associated with mortality, it is infeasible to mandate on the basis of availability and the fact that it does not distinguish between hydrostatic and inflammatory pulmonary edema. However, the results of a multi-institutional study that appeared in the previous issue of Critical Care show that this latter reservation may not necessarily be true. By using extravascular lung water and the pulmonary vascular permeability index, both of which are derived from transpulmonary thermodilution, the authors could successfully differentiate between patients with ARDS and other patients in respiratory failure due to either cardiogenic edema or pleural effusion with atelectasis. This commentary discusses the merits and limitations of this study in view of the potential improvement that transpulmonary thermodilution may bring to the definition of ARDS.
\end{abstract}

*Correspondence: perelao@shani.net

Department of Anesthesiology and Intensive Care, Sheba Medical Center, Tel Aviv University, Tel Hashomer, Tel Aviv, 52621, Israel
In the previous issue of Critical Care, Kushimoto and colleagues [1] reported on the clinical usefulness of transpulmonary thermodilution-derived extravascular lung water (EVLW) and the pulmonary vascular permeability index (PVPI) in the diagnosis of acute respiratory distress syndrome (ARDS). In an observational multi-institutional study, 266 mechanically ventilated patients with hypoxemic respiratory failure and bilateral infiltration on chest radiography were retrospectively allocated by three experts into three pathophysiological diagnostic categories: ARDS (including acute lung injury, or ALI), cardiogenic edema, and pleural effusion with atelectasis. As a first step in identifying true ARDS, a threshold value of EVLW of greater than $10 \mathrm{~mL} / \mathrm{kg}$ (of predicted body weight) was used to exclude patients who had no pulmonary edema at all (the 'atelectasis and pleural effusion' group). As a second step, the PVPI, which is the ratio of the EVLW to the pulmonary blood volume (PBV), was used to separate patients with true ARDS from those with cardiogenic edema, achieving a very high specificity in the overall diagnosis or exclusion of ARDS [1].

The concept of the PVPI is based on the fact that although EVLW may be elevated in both permeability and cardiogenic edema, the latter will also be characterized by increased preload and, as a result, a lower PVPI ratio $[2,3]$. The PVPI was originally described in an experimental study as the ratio of the EVLW to the intrathoracic blood volume (ITBV) and was found to be significantly higher in permeability compared with hydrostatic pulmonary edema [4]. In a more recent clinical study, PVPI values were significantly higher in ALI/ARDS compared with hydrostatic pulmonary edema, and a PVPI value of at least 3 allowed the diagnosis of ALI/ ARDS with high sensitivity and specificity [5]. This PVPI value is similar to the one found in the study by Kushimoto and colleagues [1] in a larger group of patients.

However, the study by Kushimoto and colleagues [1] does have a number of limitations. The most disturbing 
one is that 14 patients, who were judged by the attending experts to have respiratory failure secondary to sepsisinduced increased pulmonary vascular permeability, were excluded from the study because 'their EVLW was less than $10 \mathrm{~mL} / \mathrm{kg}$ due to hypovolemia' [1]. This somewhat unclear exclusion is seemingly unjustified and, as the authors themselves readily admit, may have biased the results of the study. The authors claim that the experts were blinded to the PVPI but not to the EVLW and the ITBV. However, since the PBV is simply one fifth of the ITBV $[2,3]$ and since the EVLW/ITBV ratio itself was originally used to calculate PVPI [4], one cannot exclude the possibility that the experts may have had some idea of the PVPI value during the exclusion and allocation processes. Other limitations of this study include the inclusion of mechanically ventilated patients only, the small size of the non-ARDS groups, the unclear pathophysiology of the atelectasis and pleural effusion group, and the absence of a calculated predictive validity of EVLW and PVPI regarding mortality.

Despite its limitations, this study [1] presents an important addition to the mounting body of recent evidence showing that EVLW improves the diagnostic accuracy of lung injury and that it is a good predictor of mortality in ALI/ARDS [6-9]. Moreover, EVLW can predict progression to ALI more than 2 days before patients at increased risk for development of ALI meet American-European Consensus Conference (AECC) criteria, providing an early opportunity to initiate lungprotective ventilation and negative fluid balance [9]. The findings of these and other studies have already led to the suggestion that EVLW $(>10 \mathrm{~mL} / \mathrm{kg})$ should be included in the definition of ARDS [9-11].

The study of Kushimoto and colleagues [1] seems very relevant to the recent ('Berlin') definition of ARDS $[12,13]$, which was aimed at overcoming the limitations of the 1994 AECC definition [10,12-16]. The most important aspects of the new 'Berlin' criteria include the introduction of three categories of ARDS (mild, moderate, severe), abandoning the term 'acute lung injury' and removing the 'wedge pressure' criterion [12-14]. Although these changes add a modicum of evidence and some simplification to the AECC definition, its concepts and components, including the reliance on the arterial partial pressure of oxygen/fraction of inspired oxygen $\left(\mathrm{PaO}_{2} / \mathrm{FiO}_{2}\right)$ ratio as the major tool for identifying and stratifying patients with ARDS, remain practically unchanged. As a result, none of the key criteria of the new definition does directly reflect its conceptual model, namely that 'ARDS is a type of acute diffuse, inflammatory lung injury, leading to increased pulmonary vascular permeability, increased lung weight, and loss of aerated lung tissue' [12]. Therefore, it is no wonder that neither the AECC nor the Berlin definition was found to be a particularly good predictor of death, with the Berlin definition offering only marginal improvement $[12,14]$.

The Berlin task force did indeed consider a number of additional measures to improve specificity and face validity for the increased pulmonary vascular permeability, including EVLW [12]. The panel concluded that although EVLW has improved face validity and higher values are associated with mortality, it is infeasible to mandate since (a) its technology is costly, invasive, and not widely available; (b) it has significant methodological limitations; and (c) it does not distinguish hydrostatic from inflammatory pulmonary edema [13]. This last reservation, at least, has now been refuted by Kushimoto and colleagues [1] and by others [5]. Previously, the AECC had used the pulmonary artery catheter (PAC) in the diagnosis of ARDS, even though it was (still is!) also invasive, costly, and not widely available and certainly had significant methodological limitations. Compared with the PAC, transpulmonary thermodilution is less invasive but provides better parameters for the diagnosis and management of ARDS. The technology has also become more available since it is not limited to one vendor anymore.

The expanded rationale of the Berlin definition of ARDS [13] concludes by saying that the direct measurement of pulmonary vascular permeability or EVLW will be an important advance over current methods of assessing the presence and origin of lung edema and could be incorporated into the future definition of ARDS. The study of Kushimoto and colleagues [1] provides another justification for taking this step.

\section{Abbreviations}

AECC, American-European Consensus Conference; ALI, acute lung injury; ARDS, acute respiratory distress syndrome; EVLW, extravascular lung water; ITBV, intrathoracic blood volume; PAC, pulmonary artery catheter; PBV, pulmonary blood volume; PVPI, pulmonary vascular permeability index.

\section{Competing interests}

AP is a member of the Medical Advisory Board of Pulsion Medical Systems, Munich, Germany.

\section{Published: 24 January 2013}

\section{References}

1. Kushimoto S, Taira Y, Kitazawa Y, Okuchi K, Sakamoto T, Ishikura H, Endo T, Yamanouchi S, Tagami T, Yamaguchi J, Yoshikawa K, Sugita M, Kase Y, Kanemura T, Takahashi H, Kuroki Y, Izumino H, Rinka H, Seo R, Takatori M, Kaneko T, Nakamura T, Irahara T, Saito N, Watanabe A, Study Group PP: The clinical usefulness of extravascular lung water and pulmonary vascular permeability index to diagnose and characterize pulmonary edema: a prospective multicenter study on the quantitative differential diagnostic definition for acute lung injury/acute respiratory distress syndrome. Crit Care 2012, 16:R232.

2. Michard F: Bedside assessment of extravascular lung water by dilution methods: temptations and pitfalls. Crit Care Med 2007, 35:1186-1192.

3. Monnet X, Perel A: Extra-vascular lung water. In Encyclopedia of Intensive Care Medicine. Edited by Vincent JL, Hall J. Berlin: Springer-Verlag; 2012:919-923.

4. Katzenelson R, Perel A, Berkenstadt H, Preisman S, Kogan S, Sternik L, Segal E: Accuracy of transpulmonary thermodilution versus gravimetric 
measurement of extravascular lung water. Crit Care Med 2004, 32:1550-1554.

5. Monnet X, Anguel N, Osman D, Hamzaoui O, Richard C, Teboul JL: Assessing pulmonary permeability by transpulmonary thermodilution allows differentiation of hydrostatic pulmonary edema from ALI/ARDS. Intensive Care Med 2007, 33:448-453.

6. Berkowitz DM, Danai PA, Eaton S, Moss M, Martin GS: Accurate characterization of extravascular lung water in acute respiratory distress syndrome. Crit Care Med 2008, 36:1803-1809.

7. Craig TR, Duffy MJ, Shyamsundar M, McDowell C, McLaughlin B, Elborn JS, McAuley DF: Extravascular lung water indexed to predicted body weight is a novel predictor of intensive care unit mortality in patients with acute lung injury. Crit Care Med 2010, 38:114-120.

8. Chew MS, Ihrman L, During J, Bergenzaun L, Ersson A, Undén J, Ryden J Åkerman E, Larsson M: Extravascular lung water index improves the diagnostic accuracy of lung injury in patients with shock. Crit Care 2012, $16: R 1$.

9. LeTourneau JL, Pinney J, Phillips CR: Extravascular lung water predicts progression to acute lung injury in patients with increased risk. Crit Care Med 2012, 40:847-854

10. Schuster DP: Identifying patients with ARDS: time for a different approach. Intensive Care Med 1997, 23:1197-1203.

11. Michard F, Fernandez-Mondejar E, Kirov MY, Malbrain M, Tagami T: A new and simple definition for acute lung injury. Crit Care Med 2012, 40:1004-1006.
12. ARDS Definition Task Force, Ranieri VM, Rubenfeld GD, Thompson BT, Ferguson ND, Caldwell E, Fan E, Camporota L, Slutsky AS: Acute respiratory distress syndrome: the Berlin Definition. JAMA 2012, 307:2526-2533.

13. Ferguson ND, Fan E, Camporota L, Antonelli M, Anzueto A, Beale R, Brochard L, Brower R, Esteban A, Gattinoni L, Rhodes A, Slutsky AS, Vincent JL, Rubenfeld GD, Thompson BT, Ranieri VM: The Berlin definition of ARDS: an expanded rationale, justification, and supplementary material. Intensive Care Med 2012, 38:1573-1582.

14. Angus DC: The acute respiratory distress syndrome. What's in a name? JAMA 2012, 307:2542-2544.

15. Marini JJ: Limitations of clinical trials in acute lung injury and acute respiratory distress syndrome. Curr Opin Crit Care 2006, 12:25-31.

16. Phua J, Stewart TE, Ferguson ND: Acute respiratory distress syndrome 40 years later: time to revisit its definition. Crit Care Med 2008, 36:2912-2921.

\section{doi:10.1186/cc11918}

Cite this article as: Perel A: Extravascular lung water and the pulmonary vascular permeability index may improve the definition of ARDS. Critical

Care 2013, 17:108 